\title{
Preparation of Ion Selective Electrode Based on Ionophore and Used to Monitor the Lead (II) Ion.
}

\author{
Hari Bhakta Oli ${ }^{1}$ and Amar Prasad Yadav ${ }^{2 *}$ \\ ${ }^{2}$ Central Depart of Chemistry, Tri-bhuvan University, Kirtipur, Kathmandu, Nepal \\ ${ }^{1}$ Amrit Campus, Tri-bhuvan University, Lainchour, Kathmandu, Nepal \\ Email: amary2y@yahoo.com
}

\begin{abstract}
:
Ionophore based lead ion sensor has been fabricated in laboratory by using thiourea as ionophore. Ionophore is a poly dented organic compound or organic anion which can bind the metal cation form their solutions. Thiourea as ionophore was taken from laboratory. The membrane was prepared using acetophenone as plasticizer. The functional parameters (slope and selectivity) of the sensor with membrane composition: (Ionophore:PVC:Plasticizer) in the ratio (1:2:6) was investigated. Sensor is characterized by direct potentiometric study, $\mathrm{pH}$ effect, potentiometric titration and selectivity coefficient. Reported selectivity coefficient for this sensor is slightly high. Sensor prepared form thiourea showed sub-Nernstian behavior of $25.07 \mathrm{mV}$ in the concentration range $10^{-1} \mathrm{M}$ to $10^{-4} \mathrm{M}$ and gives best results at the $\mathrm{pH}$ range 3-6 with measurable detection limit.
\end{abstract}

Keywords: Thiourea, ionophore, potentiometry, selectivity coefficient, detection limit

\section{Introduction}

Most of the earth's crust is made up of heavy metals. So naturally they are found in the earth's crust and easily available in the environment as a consequence of human activities and rapid industrialization. In human body, trace amounts of heavy metals are essential; however, high concentrations can be dangerous leading to a damage of human health. This is because they are non-biodegradable and can be accumulated in living tissues. Therefore, determination of trace levels of heavy metals is very critical for environmental protection, food and agricultural chemistry ${ }^{1,2}$. Lead $(\mathrm{Pb})$, is a non-physiological metal that is exposed to most of the general human population and cause clinical effects of toxicity. It has been demonstrated that it is accumulated in bone and in some soft tissues, such as liver, kidney and brain of human body ${ }^{3-6}$. The quick an exact determination of minute quantities of ionic species by simple methods has a great importance in analytical chemistry ${ }^{7-12}$. Potentiometric detection of metal ion by using ion selective electrode is the simplest one. Simple design and operation, reasonable selectivity, fast response, applicability to colored and turbid solution and low cost are some of the advantages. An ion selective electrode of a cell is an electrode in which the potential depends in the activity of a particular ionic species which it is desired to quantify. Activity of metal ion is directly proportional with concentration. The activity of metal ion is related with electromotive force (Emf) to the cell by Nernst equation. An ion selective electrode (ISE) is an electrochemical sensor with a membrane whose potential depends upon the activity of the determinant ion according to Nernst equation ${ }^{13}$.

* Corresponding author

$-101-$ 
$\mathrm{E}=\mathrm{E}_{\mathrm{o}} \pm(\mathrm{RT} / \mathrm{nF}) \ln \mathrm{a}_{\mathrm{x}}$

Where, $a_{x}$ is the activity of the determinant ion $\mathrm{X}, \mathrm{E}_{\mathrm{o}}$ is the standard potential of the cell and $\mathbf{n}$ is number of charges on $\mathrm{X}$. The sign in equation (1) is positive when $\mathrm{X}$ is cation and negative when it is an anion $^{1,13-15}$.

\section{Experimental}

Fabrication of sensor membrane:

Ionophore is a chemical compound that is used to bind the metal ion in the sensor membrane. Thiourea is selected as ionophore in this experiment.it is because thiourea contains lone pair of electrons on sulphur and nitrogen so that these pair of electrons is able to bind the free metal ions in the solution.

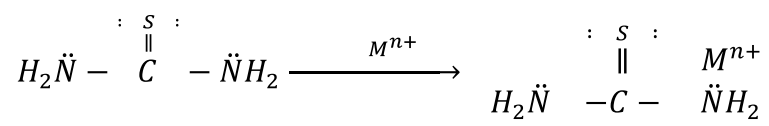

For preparing the sensor membrane, a glass tube of inner diameter $39 \mathrm{~mm}$ and outer diameter $42 \mathrm{~mm}$ with length/height $58 \mathrm{~mm}$ was taken and was fixed on a flat glass surface with epoxy resin. The homogenous solution mixture of (Ionophore:PVC:Plasticizer) in the ratio $(1: 2: 6)$ was poured inside the hollow glass tube. For the controlled evaporation and solidification of the solution the other end of the glass tube was covered with a filter paper and covered with heavy weight figure 1 .

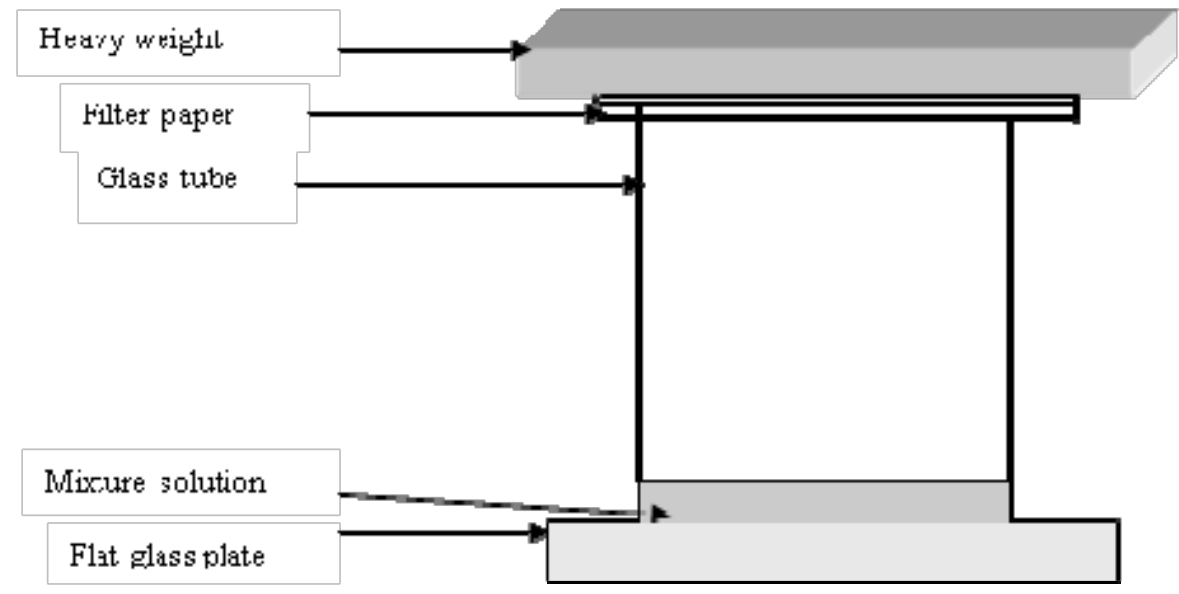

Figure 1: Experimental set up for preparation of sensing membrane.

\section{Working electrode preparation and response study}

All sample solutions were prepared by using chemical of research grade and distilled water. $\mathrm{Ag} / \mathrm{AgCl}$ reference electrode was prepared which is connected with liquid junction with sensor membrane(working electrode).Working electrode was now dipped in test solutions having different concentrations and with the help of multi-meter and calomel as reference electrode, potential of that solution was measured. Similar process was repeated for all solutions. In the similar manner potentiometric titration, interference study, dynamic response and the effect of $\mathrm{pH}$ was also studied. 


\section{Result and Discussion}

\section{Direct potentiometric study}

Potentiometric studied was carried out for sensor membrane. It is reported that in solid state ion selective electrode on addition of $\mathrm{NaNO}_{3}$, improvement in slope was seen ${ }^{2}$ but there is no significance of $\mathrm{NaNO}_{3}$ for liquid junction electrode based on ionophore. In ionophore based on ion selective electrode addition of ascorbic acid gives significant effect. Ascorbic acid controls the oxidation of metal ion and helps to detect the metal ion easily. The slope for this electrode is $25.07 \mathrm{mV}$ per decade from $10^{-2} \mathrm{M}$ to $10^{-4} \mathrm{M}$ solution.

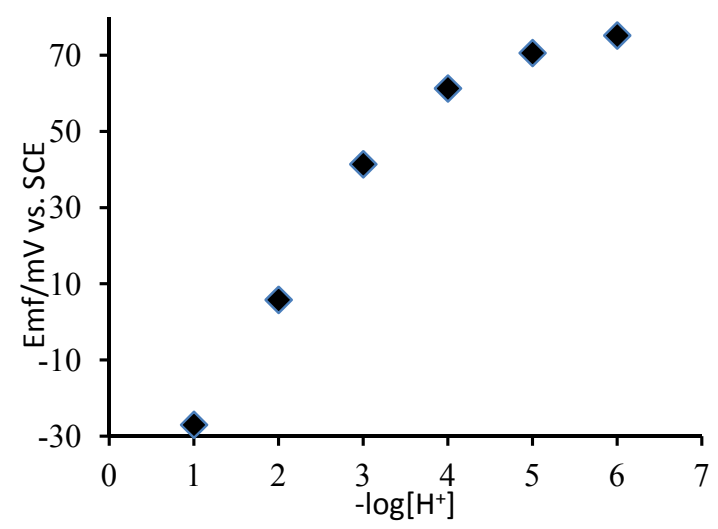

Figure 2: Emf measurement of working electrode in mixture of $\mathrm{Pb}\left(\mathrm{NO}_{3}\right)_{2}$ and ascorbic acid.

\section{Effect of pH on Sensor Membrane}

Calibration of the $\mathrm{pH}$ meter was done by using the buffer solutions of the $\mathrm{pH} 4,7 \& 9.2$ with continuous wash by distilled water. After the calibration of the $\mathrm{pH}$ meter it was ready to use and then test solution was used to test. For the study of the effect of $\mathrm{pH}$ in the potential that was used to determine by sensor membrane was varied by using solutions of acid and base. The potential of the two test solutions (strengths of $10^{-2} \mathrm{M}$ and $10^{-4} \mathrm{M}$ ) was measured by varying from $\mathrm{pH} 1$ to $\mathrm{pH} 11$.

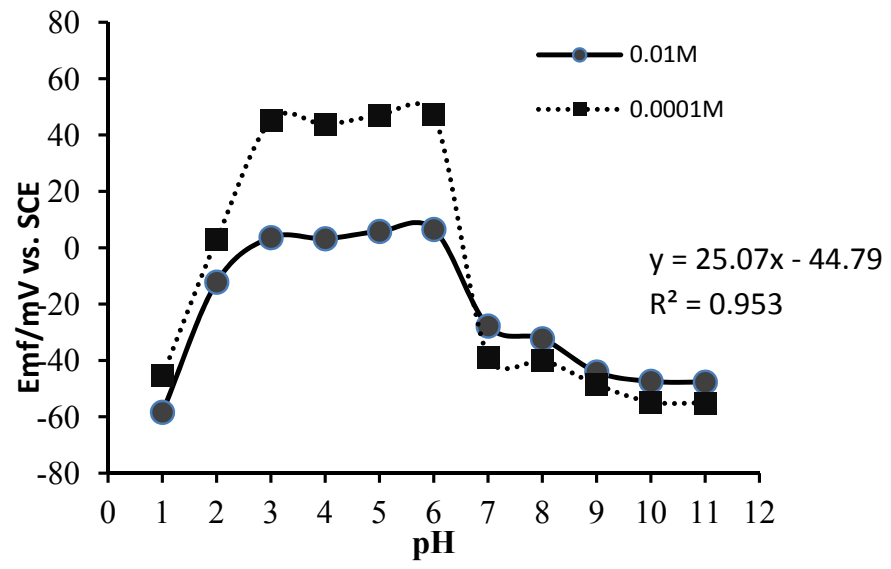

Figure 3: Potential vs. pH diagram for working electrode. 


\section{J. Nepal Chem. Soc., Vol. 36, 2017}

The potential response of the working electrode is independent in $\mathrm{pH}$ range 3.0 to 6.0 , beyond which the potential changes drastically. There is unique case for this electrode is that in high acidic and high basic medium potential is small, it is due to fact that in acidic medium proton takes the lone pair of electron from nitrogen of thiourea and there becomes deficiency of electron in sulphur due to resonance of the thiourea (ionophore in sensor membrane). So, that membrane is unable to detect lead ion at low $\mathrm{pH}$ and the value of potential is small. But, in basic medium potential is decreases due to formation of insoluble $\mathrm{Pb}(\mathrm{OH})_{2}$ on membrane surface.

\section{Dynamic Response}

For the study of dynamic response of the sensor electrode, the standard solution of $\mathrm{Pb}\left(\mathrm{NO}_{3}\right)_{2}$ with concentration of $10^{-4} \mathrm{M}$ and $10^{-2} \mathrm{M}$ were taken and the potential was measured for $2.30 \mathrm{~min}$ in each $5 / 5 \mathrm{sec}$ of time interval. The rapid response of the electrode is due to preconditioning of the sensor membrane in $1 \mathrm{mM}$ lead nitrate solution. Electrode attains equilibrium potential at 120 second of immersion time.

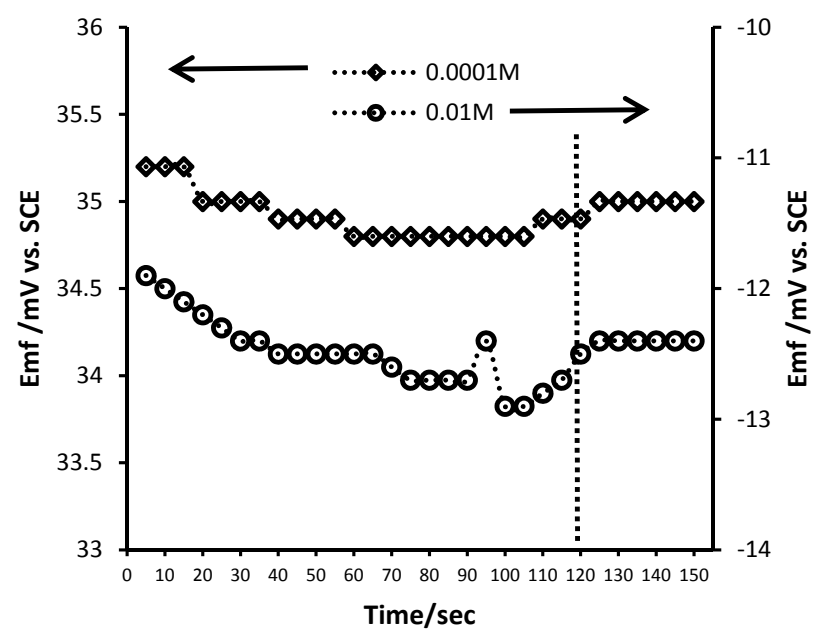

Figure 4: Dynamic response of working electrode in two different solutions of concentration $10^{-2} \mathrm{M}$ and $10^{-4}$ M lead nitrate.

\section{Potentiometric Titration}

The main application of ion selective electrode (ISE)/sensor electrode is tested by potentiometric titration of the test solution with the help of EDTA by using ISE as indictor electrode. Potential was recorded on each addition of $0.5 \mathrm{~mL}$ EDTA solution from burette to test solution. On addition of EDTA solution, the lead ion forms complex with EDTA and the concentration of lead ion decreases resulting the decrease in Emf of the solution. At equivalence point the Emf is changed drastically/significantly due to change of all lead ions in lead-EDTA complex. Further addition of EDTA doesn't changes potential as the ISE is not selective towards EDTA.

For working electrode the diagram indicates that the sharply change in potential is at equivalence point is due to addition of $5 \mathrm{~mL}$ of EDTA solution to $10^{-3} \mathrm{M} \mathrm{Pb}\left(\mathrm{NO}_{3}\right)_{2}$. There is decrease in potential difference up to $5 \mathrm{~mL}$ because EDTA consumes the concentration of metal ion form solution but at end point the metal ions are consumed completely so that potential difference is drastically changed. After 
end point the value of potential difference almost all remains constant it is because ionophore does not show affinity towards EDTA.

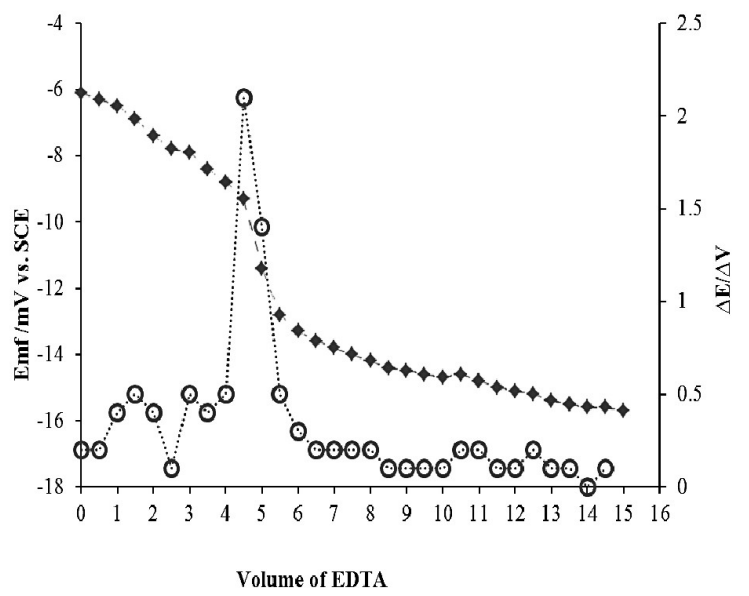

Figure 5: Potentiometric titration of $10^{-3} \mathrm{M}$ lead nitrate with EDTA solution.

\section{Selectivity Coefficient}

There are various methods for the measurement of potentiometric selectivity coefficients of ion selective electrodes. There are mixed solution methods and separate solution methods for determination of selectivity coefficient. Mixed solution method includes: fixed interference method(FIM), fixed primary ion method(FPM), two solution method(TSM) and matched potential method(MPM). Similarly, separate solution method includes two conditions $\left(a_{A}=a_{B}\right)$ and $\left(E_{A}=E_{B}\right)$. Where, $a_{A}$ and $a_{B}$ are activity of primary and interfering ion also $\mathrm{E}_{\mathrm{A}}$ and $\mathrm{E}_{\mathrm{B}}$ are emf of primary and interfering ions.

Among all MPM is being more convenient and reliable, this method is followed in this research to determine the selectivity of lead ion sensor electrodes. In this method, the potentiometric selectivity coefficient is defined as the activity ratio of primary and interfering ions that give the same potential change under identical conditions. At first, a known activity $\left(\mathrm{a}_{\mathrm{A}}{ }^{\prime}\right)$ of the primary ion solution is added into a reference solution that contains a fixed activity $\left(\mathrm{a}_{\mathrm{A}}\right)$ of primary ions, and the corresponding potential change $(\Delta \mathrm{E})$ is recorded. Next, a solution of an interfering ion is added to the reference solution until the same potential change $(\Delta \mathrm{E})$ is recorded. The change in potential produced at the constant background of the primary ion must be the same in both cases [16].

$$
\begin{aligned}
& \mathrm{K}^{\mathrm{pot}}{ }_{\mathrm{A}, \mathrm{B}}=\left(\mathrm{a}_{\mathrm{A}}{ }^{\prime}-\mathrm{a}_{\mathrm{A}}\right) / \mathrm{a}_{\mathrm{B}} \\
& \text { Or, } \mathrm{K}^{\mathrm{pot}}{ }_{\mathrm{A}, \mathrm{B}}=\Delta \mathrm{A} / \mathrm{B}
\end{aligned}
$$

Where, $\Delta \mathrm{A}$ is change in activity of primary solution and reference solution. $\mathrm{B}$ is the concentration of interference ion.

This effect is studied for this ion selective electrode in interfering ions like $\mathrm{Cd}\left(\mathrm{NO}_{3}\right)_{2}, \mathrm{Cu}\left(\mathrm{NO}_{3}\right)_{2}$, $\mathrm{Ni}\left(\mathrm{NO}_{3}\right)_{2}, \mathrm{AgNO}_{3}, \mathrm{NH}_{4} \mathrm{NO}_{3}, \mathrm{Co}\left(\mathrm{NO}_{3}\right)_{2}$ and tabulated in the table 1 . For interference study $0.001 \mathrm{M}$ solutions of the nitrate salts of the mentioned cations are taken and added in $10^{-4} \mathrm{M}$ lead nitrate solution and the change in potential is noted for calculation.

$-105-$ 
Table1: Selectivity coefficient of working electrode.

\begin{tabular}{|c|c|}
\hline Interfering ions & $\log \mathrm{K}_{\mathrm{A}, \mathrm{B}}^{\text {pot }}=\log (\Delta \mathrm{A} / \mathrm{B})$ \\
\hline $\mathrm{Ag}^{+}$ & 2.27 \\
\hline $\mathrm{Cu}^{2+}$ & 2.06 \\
\hline $\mathrm{Cd}^{2+}$ & 2.00 \\
\hline $\mathrm{Ni}^{2+}$ & 1.91 \\
\hline $\mathrm{Co}^{2+}$ & 1.91 \\
\hline $\mathrm{NH}_{4}^{+}$ & 1.90 \\
\hline
\end{tabular}

Though the result shows interference by other ions but these results are not overly surprising, since similar findings are reported earlier in cadmium ion selective electrode ${ }^{19}$ and lead ion selective electrode ${ }^{18}$ by E. Bakker.

\section{Conclusions}

Lead ion sensor is fabricated in laboratory in this research by simple method using PVC plasticizing membrane with ionophore. The liquid contact in the working electrode is made by using $0.1 \mathrm{M}$ lead nitrate solution. These electrodes fabricated in laboratories are found to be well behaved and the selectivity coefficient of electrode is found to be as expected.

The working electrode give linear curve with sub-Nernstian slope of $25.07 \mathrm{mV}$ per decade and very fast dynamic response with detection limit is only $10^{-5} \mathrm{M}$. Thus, constructed lead ion sensor in our laboratory performs semi-Nernstian behavior, fast respond and of expected selectivity. This is applicable for the detection of lead ion in water as well soil samples, due to its applicable detection limit.

\section{Acknowledgements}

The authors are grateful to University Grants Commission (UGC) for providing research grant and for Central Department of Chemistry, Tribhuvan University Kirtipur, Kathmandu and Department of Chemistry, Tri-Chandra Multiple Campus, to carry out this research work.

\section{References}

1. A.P. Yadav, Preparation and analytical study of some silver sulfide based ion-selective electrodes. A dissertation submitted to Central Department of Chemistry, Tribhuvan University, 1995.

2. K.R. Ojha, Preparation and Response characterization of all solid state sensor for Pb(II). A dissertation submitted to Central Department of Chemistry, Tribhuvan University, 2012

3. B.S. Bahl, Arun Bahl and G.D. Tuli, Essentials of physical chemistry $1^{\text {st }}$ edition, S. Chand and company limited India, reprint 2006, p. 856-869.

4. A.R. Elsalamouny, S.A. Elreefy and A.M.A. Hassan, Research J. of Chem. Sci., June 2012, 2(6), $38-42$.

5. F.A. Cotton, G. Wilkinson, C.A. Murillo and M. Bochmann, Advanced inorganic chemistry $6^{\text {th }}$ edition, reprint 2008, 258-308. 
6. J. Mendham, R.C. Denney, J.D. Barnes, M.K.J. Thomas, Vogel's text book of quantitative chemical analysis, longman publication, $6^{\text {th }}$ edition, 2007, 540-550.

7. A.J. Bard, C.R. Faulkner, Electrochemical methods fundamentals and applications, second edition, USA, 74-82.

8. S.H. Maron and C. F. Prutton, Principles of Physical Chemistry, Fourth Edition, Oxford and IBH publishers Co. Pvt. Ltd.

9. P. Atkins and J.D. Paula, Atkins Physical Chemistry, $8^{\text {th }}$ edition, Oxford University Press, 2002, 988-991.

10. A. Craggs, G.J. Moody and J.D.R. Thomas, J. of Chem. Edu., August 1974, 51, 541-544.

11. Richard P. Buck and Erno Lindner, Acc. Chem. Res., 1998, 31 (5), 257-266.

12. E. Malinowska, W. Wroblewski, R. Ostaszewski and J. Jurczak, Polish J. Chem., 2000, 74, 701706 .

13. A. Arnold Mark and M. E. Meyerhoff, Anal. Chem., 1984, 56, 20R-48R.

14. M.H. Rizk Nashwa, S. Abbas Samah, M. Hamza Salem and M. Abd EL-Karem Yasser, J. on Sens., 2009, 9, 1860-1875.

15. D. Vlascici, E.F. Cosma, E.M. Pica, V. Cosma, O. Bizerea, G. Mihailescu and L. Olenic, Chem. Sens., 2008, 4995-5004.

16. Yoshio Umezawa, Philippe Bühlmann, Kayoko Umezawa, Koji Tohda, And Shigeru Amemiya, Pure Appl. Chem., 2000, 72, 1851-2082.

17. M.K. Sthapit, R.R. Pradhananga and K.B. Bajracharya, Foundation of Chemistry, Taleju Prakashan, 2061, 291-292.

18. E. Bakker, M. Lerchi, B. Rusterholz and W. Simon, Anal. Chem. 1992, 64, 1534.

19. E. Bakker, L.V. Kochian, J.E. Shaff and M.A. Pineros, Electrolysis, 1998, 10, 938-941. 